\title{
Kuminaöljy porsaiden vieroitusripulin ehkäisyssä
}

\author{
Hilkka Siljander-Rasi ${ }^{1)}$, Kirsi Partanen ${ }^{1)}$ ja Marjo Keskitalo ${ }^{2)}$ \\ ${ }^{1)}$ MTT Sikatalous, Tervamäentie 179,05840 Hyvinkää, etunimi.sukunimi@mtt.fi \\ ${ }^{2)}$ MTT Kasvinviljely ja biotekniikka,31600Jokioinen, marjo.keskitalo@mtt.fi
}

\section{Johdanto}

Antibioottisten kasvunedistäjien sijasta porsaiden rehuihin lisätään useita eri aineita, joilla on todettu tai uskotaan olevan ripulia ehkäiseviä vaikutuksia. Vaikutukset ovat joko antimikrobisia (esim. orgaaniset hapot, eteeriset öljyt), kolibakteerien kiinnittymistä estäviä (esim. oligosakkaridit) tai fysikaalisia/mikrobitoimintaa tasapainottavia (esim. vettä sitovat, pektiinipitoiset kuituvalmisteet).

Useimpiin kaupallisiin porsasrehuihin lisätään orgaanisia happoja, yleisimmin muurahaishappoa tai siihen perustuvia happoseoksia. Muurahaishappo on rehun säilöntäaine, mutta sillä on myös kasvua edistävää ja ripulia torjuvaa vaikutusta. Se parantaa myös rehun ravintoaineiden sulavuutta. Käyttömäärä on 6-10 g/kg rehua. Suuremmat käyttömäärät huonontavat rehun syöntiä ja ovat lopulta haitallisia (Partanen \& Mroz 1999).

Yrttejä ja kasviuutteita, ns. fytogeenisia aineita, on runsaasti tarjolla myös sikojen rehuihin. Niiden antimikrobiset ominaisuudet ovat haihtuvissa eli eteerisissä öljyissä, jotka saadaan erotettua tislaamalla. Muutamia positiivisia koetuloksia yrttivalmisteiden tehosta sikojen kasvun edistäjinä on julkaistu (Grela ym. 1998). Kumina on sarjakukkainen kasvi. Suomessa viljeltävä kaksivuotinen muoto tuottaa ensimmäisenä vuotena lehtiruusukkeen ja toisena vuotena kukkii ja muodostaa siemenet. Kuminan siemenet sisältävät haihtuvia öljyjä. Niitä on perinteisesti käytetty vatsa- ja ilmavaivojen hoidossa, säilönnässä sekä elintarvikkeiden ja juomien maustamiseen. Kuminaöljy sisältää S-karvonia ja limoneeniterpeenejä, joista erityisesti karvonilla on havaittu olevan $\mathrm{mm}$. perunan itämistä ja mikrobien kasvua estävää vaikutusta (Oosterhaven ym 1995).

Vieroitusripulin yleisin aiheuttaja on hemolyyttinen E. coli -bakteeri. Sen määrää suolistossa on pyritty vähentämään sekoittamalla porsaiden rehuun aineita, jotka kiinnittyvät ohutsuolen seinämään E. colin sijasta, tai joihin bakteeri kiinnittyy ja kulkeutuu ulos suolistosta. Tällaisia valmisteita on kehitetty mm. hiivojen solunseinämien oligosakkarideista (Bolduan 1997). Suomessa on kehitetty hiivavalmiste Pigaride, jonka avulla pyritään vähentämään $E$. coli K88:n kiinnittymistä porsaiden ja broilereiden ohutsuolen limakalvolle ja aktivoimaan suoliston immuniteettia.

Ripulin ennaltaehkäisyyn suositellaan myös kuituvalmisteita, koska kuidun uskotaan edistävän hyödyllisen suolistomikrobiston kehittymistä sekä sitovan itseensä haitallisia aineita suolistossa. Esimerkiksi perunasta ja sokerijuurikkaasta saadaan puhdistamalla vettä hyvin sitovaa kuitua, joka sisältää runsaasti pektiiniä ja hemiselluloosaa (Göransson 1997).

Tämän tutkimuksen tarkoituksena oli verrata erityyppisten rehun raaka-aineiden tehokkuutta vieroitettujen porsaiden vieroitusripulin ehkäisyssä ja niiden vaikutusta kasvuun ja rehuhyötysuhteeseen kolme viikkoa vieroituksesta. Koevaiheen jälkeen porsaiden menestymistä seurattiin välitysikään saakka.

\section{Aineisto ja menetelmät}

Kuminaöljyn käyttömäärän selvittämiseksi järjestettiin esikoe. Siinä oli kuusi pahnuetta. Pahnueet jaettiin vieroituksen jälkeen puoliksi. Toinen pahnueen puolikas sai rehussaan $40 \mathrm{mg} / \mathrm{kg}$ ja toinen 80 $\mathrm{mg} / \mathrm{kg}$ kuminaöljyä. Haihtumisen estämiseksi öljy sekoitettiin ruokintakalkkiin ennen rehun sekoitusta (80 g öljyä ja 720 g kalkkia/1000 kg). Testi kesti 10 päivää vieroituksesta. Kuminaöljyn määrä rehussa ei vaikuttanut porsaiden rehun syöntiin, joten kuminaöljyn määräksi valittiin $80 \mathrm{mg} / \mathrm{kg}$ rehua.

Varsinaisessa kokeessa oli 40 pahnuetta (384 porsasta). Pahnueista 20 oli vieroitettu 28 päivän iässä tai nuorempina ja 20 yli 28 päivän iässä. Pahnue jaettiin kahteen karsinaan ja karsinat jaettiin viiteen koeryhmään epätäydellisten lohkojen koemallin mukaisesti. Kuhunkin ryhmään tuli kahdeksan karsinaa molemmista vieroitusikäryhmistä (66-89 porsasta/ryhmä). Koekäsittelyt olivat 1) Lisäaineeton porsasrehu, perusrehu 2) Perusrehuun lisätty $8 \mathrm{~g} / \mathrm{kg}$ muurahaishappoa (AIV II+, Kemira Chemicals) 3) Perusrehuun lisätty $3 \mathrm{~g} / \mathrm{kg}$ prosessoitua hiivaa (Pigaride, Suomen Rehu Oy) 4) Perusrehuun lisätty $80 \mathrm{mg} / \mathrm{kg}$ kuminaöljyä ja 5) Perusrehuun lisätty $20 \mathrm{~g} / \mathrm{kg}$ perunakuitua (Povex, T+ Oy).

Koerehujen koostumus näkyy taulukossa 1. Kaikki rehut rakeistettiin. Kaikki porsaat saivat ennen vieroitusta perusrehua kahden viikon iästä alkaen. Vieroituksen jälkeen porsaille annettiin koere- 
huja vapaasti automaatista 21 päivän ajan. Sen jälkeen kaikki koeryhmät siirtyivät välikasvatusrehulle, jossa ei ollut porsasrehuissa käytettyjä aineita. Koe päättyi, kun porsaat olivat 70 päivän ikäisiä.

Taulukko 1. Koerehujen raaka-aineet (g/kg) ja laskettu koostumus.

\begin{tabular}{lcc}
\hline & Porsasrehu & Välikasvatusrehu \\
\hline Ohra & 300,0 & 795,4 \\
Vehnä & 470,4 & - \\
Kaurahiutale & 70,0 & - \\
Soijarouhe & 77,6 & 154,2 \\
Kalajauho & 30,0 & 20,0 \\
Heraproteiinijauhe & 20,0 & - \\
L-lysiini- HCl & 3,3 & 2,2 \\
DL-metioniini & 0,5 & 0,3 \\
L-treoniini & 0,7 & 0,3 \\
Monokalsiumfosfaatti & 4,3 & 5,0 \\
Ruokintakalkki & 10,4 & 10,4 \\
Kivennäis-vitamiiniseos & 12,9 & 12,2 \\
Laskettu koostumus & & \\
Rehuyksikköarvo, ry/kg & 1,01 & 0,95 \\
Raakavalkuainen, g/kg & 166 & 174 \\
Sulava raakavalkuainen, g/ry & 142 & 150 \\
Sulava lysiini, g/ry & 9,5 & 9,5 \\
Sulava metioniini+kystiini, g/ry & 5,6 & 5,6 \\
Sulava treoniini, g/ry & 5,7 & 5,7 \\
Sulava tryptofaani, g/ry & 1,8 & 1,9 \\
Kalsium, g/ry & 8,00 & 8,50 \\
Sulava fosfori, g/ry & 2,86 & 3,04 \\
\hline
\end{tabular}

Ripulin esiintymistä seurattiin päivittäin. Ripulijakson kestoksi katsottiin ensimmäisen ja viimeisen ripulihavainnon välinen aika. Ripuli-indeksi laskettiin kaavalla indeksi $=\Sigma$ (ulosteen kiinteysaste (0-3) x esiintyminen, pv). Tarkkailu oli karsinakohtainen. Porsailta otettiin sontanäyte viiden ja yhdeksän päivän kuluttua vieroituksesta. Yhteisnäyte otettiin joka ryhmän 14 karsinasta, kolmelta karsinan porsaalta (samat porsaat molemmilla kerroilla).

Koerehuista tehtiin rehuanalyysi ja mitattiin kuminaöljyn määrä eurooppalaisen farmakopean mukaisen vesihöyrytislauksen avulla. Sontanäytteistä määritettiin kuiva-aine.

Aineiston tilastollinen analyysi tehtiin SAS-ohjelmistolla (MIXED). Mallissa oli mukana vieroitusiän ja ruokinnan vaikutukset sekä niiden yhdysvaikutus. Vieroitusiän vaikutusta testattaessa virheterminä oli pahnueen satunnainen vaikutus vieroitusiän sisällä. Havaintoyksikkönä oli karsina. Koekäsittelyjä 2-5 verrattiin lisäaineettomaan rehuun (käsittely 1) Dunnettin testillä.

\section{Tulokset ja tulosten tarkastelu}

Kuminaöljyn säilyvyydestä rehussa ei saatu tietoa, koska öljyn vesihöyrytislaus rehuseoksesta ei onnistunut. Todennäköisesti määritys tulisi tehdä liuottimen avulla. Kuminaöljy tai muut tutkitut rehun raaka-aineet eivät vaikuttaneet merkitsevästi porsaiden kasvuun ja rehunkäyttöön (taulukko 2). Kokeen päättyessä, 70 päivän iässä, eri rehuilla kolme viikkoa vieroituksesta ruokitut porsaat olivat keskimäärin samanpainoisia $(20,1 \mathrm{~kg}, 20,3 \mathrm{~kg}, 20,0 \mathrm{~kg}, 20,4 \mathrm{~kg}$ ja 19,8 kg ryhmissä 1-5). Kuminaöljyn haju ja maku olivat aistittavissa rehussa selvästi, mutta rehunkulutuksen perusteella porsaat eivät vieroksuneet sitä. Porsaiden rehuhyötysuhteet olivat varsin suuria, mikä johtui sekä rehun haaskauksesta automaateista että vieroitusripulin esiintymisestä kokeen aikana. Eniten rehun tuhlausta (rehuhyötysuhde yli $3 \mathrm{~kg} / \mathrm{kasvukg}$ ) oli kontrolliryhmässä (6/16 karsinassa) ja vähiten muurahaishapporyhmässä (3/18 karsinassa). Rehuhyötysuhteessa havaittiin yhdysvaikutus vieroitusiän ja ruokinnan välillä: yli 28 päivän iässä vieroitetuilla, muurahaishappoa tai Pigaride-hiivavalmistetta saaneilla porsailla rehuhyötysuhde oli parempi kuin kontrolliryhmän porsailla $(\mathrm{p}<0,10)$. Nuorempina vieroitetuilla porsailla rehuhyötysuhteet eivät poikenneet kontrolliryhmän tuloksista. Yrttivalmisteiden tehoa (oreganoja valkosipuli) porsailla ei pystytty myöskään osoittamaan Perttilän ym. (2002) tutkimuksessa. Muidenkin kasvua edistävien aineiden, esimerkiksi orgaanisten happojen tehokkuus on porsailla vaihtelevampi kuin lihasioilla (Partanen \& Mroz 1999).

Toteutunut vieroitusikä oli alle 28 päivän vieroitusiän porsailla keskimäärin 25,7 päivää ja yli 28 päivän vieroitusiän porsailla 33,5 päivää. Jälkimmäisen ryhmän ikä oli lähellä suomalaisten tark- 
kailutilojen keskimääräistä vieroitusikää (34 päivää v. 2002). Ryhmävieroituksessa osa porsaista vieroitetaan käytännössä alle 28 päivän iässä. EU:ssa vieroitusikäsuositus on 28 päivää, mutta asianmukaista vieroitusosastoa käytettäessä porsaiden vieroitus sallitaan jo 21 päivän iässä (MMM asetus 14/EEO/2002). Vieroitusikä vaikutti porsaiden kasvuun, joka oli $180 \mathrm{~g} / \mathrm{pv}$ nuorempina ja $296 \mathrm{~g} / \mathrm{pv}$ vanhempina vieroitetuilla porsailla $(\mathrm{p}<0,001)$. Kokeen päättyessä, 70 päivän iässä, alle 28 päivän iässä vieroitetut porsaat olivat edelleenkin kevyempiä kuin myöhemmin vieroitetut $(19,0 \mathrm{~kg}$ vs. $21,2 \mathrm{~kg}$; $\mathrm{p}<0,05)$. Yli 28 päivän iässä vieroitetut porsaat söivät enemmän rehua, $0,828 \mathrm{vs.} 0,680 \mathrm{~kg} / \mathrm{pv}$ vieroituksesta 70 päivän ikään $(\mathrm{p}<0,01)$. Vieroitusikä ei vaikuttanut rehuhyötysuhteeseen.

Ripulin vakavuutta kuvaavassa ripuli-indeksissä havaittiin merkitsevä yhdysvaikutus ruokinnan ja vieroitusiän välillä: alle 28 päivän iässä vieroitetuilla, hiivavalmistetta saaneilla porsailla ripuliindeksi oli suurempi kuin lisäaineettomalla rehulla ruokittaessa $(p<0,01)$, mutta vanhemmassa vieroitusikäryhmässä tätä eroa ei havaittu. Ripulihavainnot ajoittuivat myös pitemmälle aikavälille kuin kontrolliryhmässä, kun Pigaridea käytettiin nuoremmille porsaille $(\mathrm{p}<0,05)$. Vanhempina vieroitetuilla porsailla koekäsittelyt eivät vaikuttaneet ripulin kestoon. Kuminaöljyä, muurahaishappoa tai perunakuitua käytettäessä ripuli-indeksi tai ripulin kesto eivät poikenneet lisäaineetonta rehua saaneiden porsaiden tuloksista. Kokeen aikana kuoli tai lopetettiin kaikkiaan kahdeksan porsasta $(2,1 \%)$, joista viisi oli nuoremmasta vieroitusikäryhmästä. Yleisin kuolinsyy oli ripuli (7/8 porsaasta). Perunakuitua saaneesta ryhmästä ei kuollut porsaista.

Taulukko 2. Porsaiden tuotantotulokset ja vieroitusripulin esiintyminen ruokittaessa ripulia ehkäiseviä raaka-aineita sisältävillä rehuilla 21 päivää vieroituksesta.

\begin{tabular}{|c|c|c|c|c|c|c|c|c|c|}
\hline & \multirow[b]{2}{*}{ Kontrolli } & \multirow{2}{*}{$\begin{array}{l}\text { Muurahais- } \\
\text { happo }\end{array}$} & \multirow{2}{*}{$\begin{array}{l}\text { Hiivavalm. } \\
\text { Pigaride }\end{array}$} & \multirow{2}{*}{$\begin{array}{l}\text { Kumina- } \\
\text { öljy }\end{array}$} & \multirow{2}{*}{$\begin{array}{l}\text { Peruna- } \\
\text { kuitu }\end{array}$} & \multirow[b]{2}{*}{ SEM } & \multicolumn{3}{|c|}{ Tilast. merkits. } \\
\hline & & & & & & & $\mathrm{R}$ & $\mathrm{V}$ & $\mathrm{RxV}$ \\
\hline Vieroituspaino, kg & 9,3 & 9,0 & 9,2 & 9,3 & 9,0 & 0,25 & & $* * *$ & \\
\hline$\leq 28 \mathrm{pv}$ vieroitus & 7,8 & 7,6 & 7,7 & 7,8 & 7,8 & 0,35 & & & \\
\hline$>28$ pv vieroitus & 10,8 & 10,5 & 10,6 & 10,8 & 10,3 & 0,36 & & & \\
\hline Elopaino, kg & 14,1 & 14,4 & 14,1 & 14,3 & 14,0 & 0,46 & & $* * *$ & \\
\hline$\leq 28 \mathrm{pv}$ vieroitus & 11,7 & 11,6 & 11,2 & 11,5 & 11,7 & 0,65 & & & \\
\hline$>28 \mathrm{pv}$ vieroitus & 16,5 & 17,2 & 17,0 & 17,1 & 16,2 & 0,66 & & & \\
\hline Päiväkasvu, g & 225 & 254 & 234 & 241 & 235 & 15,6 & & $* * *$ & \\
\hline$\leq 28 \mathrm{pv}$ vieroitus & 183 & 187 & 161 & 180 & 188 & 20,7 & & & \\
\hline$>28 \mathrm{pv}$ vieroitus & 266 & 321 & 307 & 302 & 282 & 22,1 & & & \\
\hline Rehua, g/porsas/pv & 629 & 549 & 556 & 616 & 578 & 0,04 & & $* * *$ & \\
\hline$\leq 28 \mathrm{pv}$ vieroitus & 521 & 446 & 440 & 480 & 443 & 0,06 & & & \\
\hline$>28 \mathrm{pv}$ vieroitus & 737 & 653 & 672 & 751 & 713 & 0,06 & & & \\
\hline Rehuhyötysuhde, & & & & & & & & & \\
\hline $\mathrm{kg} / \mathrm{kasvukg}$ & 3,12 & 2,31 & 2,68 & 2,69 & 2,69 & 0,25 & & & \\
\hline$\leq 28 \mathrm{pv}$ vieroitus & 2,84 & 2,50 & 3,19 & 2,57 & 2,73 & 0,35 & & & \\
\hline$>28$ pv vieroitus ${ }^{1}$ & 3,40 & $2,13 \mathrm{c}$ & $2,16 \mathrm{c}$ & 2,80 & 2,64 & 0,35 & & & \\
\hline Ripuli-indeksi & 9,9 & 11,8 & 12,2 & 11,6 & 8,9 & 1,75 & & $*$ & $* *$ \\
\hline$\leq 28 \mathrm{pv}$ vieroitus & 9,8 & 13,2 & $19,7 \mathrm{a}$ & 15,7 & 10,0 & 2,46 & & & \\
\hline$>28 \mathrm{pv}$ vieroitus & 10,0 & 10,4 & 4,8 & 7,5 & 7,9 & 2,49 & & & \\
\hline Ripulin kesto, pv & 6,4 & 9,2 & 9,7 & 7,2 & 8,2 & 1,34 & & & o \\
\hline$\leq 28 \mathrm{pv}$ vieroitus & 5,5 & 9,0 & $13,1 b$ & 8,8 & 8,2 & 1,90 & & & \\
\hline$>28$ pv vieroitus & 7,4 & 9,5 & 6,3 & 5,6 & 8,3 & 1,91 & & & \\
\hline Sonnan vesi, $\mathrm{g} / \mathrm{kg}$ & & & & & & & & & \\
\hline 5. pv vieroituksesta & 725 & 714 & 677 & 707 & 707 & 1,85 & & & \\
\hline$\leq 28 \mathrm{pv}$ vieroitus & 727 & 696 & 662 & 726 & 718 & 2,69 & & & \\
\hline$>28 \mathrm{pv}$ vieroitus & 722 & 732 & 691 & 688 & 696 & 2,53 & & & \\
\hline 9. pv vieroituksesta & 701 & 732 & 751 & 745 & 742 & 2,11 & & & \\
\hline$\leq 28 \mathrm{pv}$ vieroitus & 729 & 741 & 771 & 729 & 728 & 2,98 & & & \\
\hline$>28$ pv vieroitus & 673 & 723 & 731 & 760 & 755 & 2,98 & & & \\
\hline
\end{tabular}

Merkitsevä ero kontrolliryhmään vieroitusiän sisällä, a: $p<0,01, b$ : $p<0,05$, c:p $<0,10$.

Orgaaniset hapot ovat joissakin tutkimuksissa vähentäneet vieroitusripulia, mutta niiden tehokkuus on ollut pienempi kuin varsinaisten antibioottisten kasvunedistäjien (Partanen \& Mroz 1999). Yrtti-, hiiva- ja kuituvalmisteiden vaikutuksesta ripuliin on vähemmän julkaistua tietoa. Vieroitusripulin puhkeamiseen vaikuttavat ruokinnan lisäksi monet ympäristötekijät ja eläimen vastustuskyky. 


\section{Johtopäätökset}

Tässä tutkimuksessa käytetyillä rehun raaka-aineilla lisäaineilla ei saatu hyötyä lisäaineettomaan rehuun verrattuna porsaiden ruokinnassa. Kuminatuotteiden käyttömahdollisuudet porsasrehuissa olisi kuitenkin syytä vielä tarkemmin selvittää. Kuminan siementen käyttö sikojen vieroitusripulin torjuntaan on tunnettu Suomessa kansanlääkinnässä. Lisäys öljynä ei käytännössä onnistune suuren haihtuvuuden ja tuotteen kalliin hinnan vuoksi.

Vieroitusiän aikaistaminen vaikutti haitallisesti porsaiden kasvuun. Jos porsaat vieroitetaan alle 28 päivän iässä, ympäristöolosuhteisiin ja ruokintaan on kiinnitettävä erityistä huomiota. Vieroitusripulia esiintyi alle 28 päivän iässä vieroitetuilla porsailla enemmän hiivavalmistetta käytettäessä kuin kontrolliruokinnalla. Muut ripulin ehkäisyyn tarkoitetut rehun raaka-aineet eivät vaikuttaneet ripulin esiintymiseen.

\section{Kirjallisuus}

Bolduan, G. 1997. Feed prophylaxis against piglet diarrhoea. Kraftfutter 1997 (12): 517-521.

Grela, E.R., Krusinski, R. \& Matras, J. 1998. Efficacy of diets with antibiotic and herb mixture additives in feeding of growing-finishing pigs. J. Anim. Feed Sci. 7: 171-175.

Göransson, L. 1997. Alternatives to antibiotics - the influence of new feed strategies for pigs on biology and performance. In: Garnsworthy, P.C. \& Wiseman, J. (eds.). Recent developments in pig nutrition 3. Nottingham University Press, UK. p. 39-50.

Oosterhaven, K., Poolman, B. \& Smid, E.J. 1995. S-Carvone as a naturalsprout inhibiting, fungistatic and bacreristatic compound. Indust. Crops Prod. 4: 23-31.

Partanen, K. \& Mroz, Z. 1999. Organic acids for performance enhancement in pig diets. Nutr. Res. Rev. 12: 117-145.

Perttilä, S., Partanen, K., Siljander-Rasi, H. \& Laurinen, P. 2002. Yrttien vaikutus porsaiden vieroitusripulin esiintymiseen. Tutkimusraportti. MTT Sikatalous, Hyvinkää. 5 p. 